\title{
Perbedaan antara Jenis dan Derajat Kelainan Jantung serta Jenis Persalinan Terhadap Outcome Ibu dan Bayi pada Kehamilan dengan Penyakit Jantung
}

\author{
Cytta Nirmala, ${ }^{1}$ Johanes C. Mose, ${ }^{2}$ Muhammad Alamsyah Aziz, ${ }^{2}$ \\ Jusuf Sulaeman Effendi, ${ }^{2}$ Benny Hasan Purwara, ${ }^{2}$ Adhi Pribadi ${ }^{2}$ \\ ${ }^{1}$ RSUD Sangir, Kab Gayo Lueh, Nanggroe Aceh Darussalam \\ ${ }^{2}$ Departemen Obstetri dan Ginekologi Fakultas Kedokteran Universitas Padjadjaran \\ Rumah Sakit Dr. Hasan Sadikin Bandung \\ korespondensi: Cytta Nirmala, email: cyttanirmala@gmail.com
}

\begin{abstract}
Abstrak
Tujuan: Penelitian ini dilakukan upaya untuk menilai karakteristik dan outcome kehamilan dengan kelainan jantung baik pada ibu dan bayi di RSUP dr. Hasan Sadikin Bandung dari tahun 2015 sampai 2017.

Metode: Penelitian ini merupakan penelitian observasional analitik (cross-sectional). Subjek penelitian adalah semua ibu hamil dengan kelainan jantung yang menjalani persalinan di RSUP dr. Hasan Sadikin Bandung dari tahun 2015 - 2017 dengan menggunakan data sekunder.

Hasil: Selama periode penelitian sebanyak 76 sampel penelitian yang diperoleh. Pada penelitian ini usia ratarata ibu adalah 30 tahun, paling banyak pada paritas 1 dan 3 yaitu sebesar $31,6 \%$. Usia kehamilan saat terjadi persalinan $>37$ minggu sebanyak 53,9\%. Lama perawatan pasien rata-rata 7 sampai 8 hari dengan ruang rawat yang paling banyak adalah ICU sebanyak 32,9\%, dan ruang rawat biasa sebesar $39.5 \%$. Jenis kelainan jantung yang paling sering adalah kardiomiopati peripartum dan hipertensi, yaitu sebesar $42,1 \%$. Jenis persalinan yang banyak dilakukan adalah seksio sesarea yaitu sebesar $64,5 \%$. Penelitian ini memperoleh bahwa ibu dengan kelainan jantung yang hidup sebesar $88,2 \%$ dan meninggal sebesar $11,8 \%$ setelah menjalani persalinan.

Kesimpulan: Ada perbedaan antara derajat kelainan jantung berdasarkan NYHA (New York Heart Association) dengan outcome ibu dan bayi pada kehamilan dengan kelainan jantung.
\end{abstract}

Kata kunci: Jenis dan Derajat Kelainan Jantung, Jenis Persalinan, Outcome Ibu dan Bayi

\section{Differences between Types and Degrees of Heart Disorders and Types of Labor in the Outcome of Mothers and Babies in Pregnancy with Heart Disease}

\begin{abstract}
Objective: through this research conducted efforts to assess the characteristics and outcome of pregnancy with cardiac disease both in mother and infant in dr dr. Hasan Sadikin Bandung from year 2015 to 2017.

Method: an observational analytic (cross-sectional) research with subjects were all pregnant women with cardiac abnormalities who underwent delivery at dr. Hasan Sadikin Bandung from 2015 to 2017 using secondary data.

Results:During the research period as many as 76 samples obtained. In this study the average age of the mother is 30 years, most at parity 1 and 3 that is equal to 31.6\%, age of pregnancy during labor $>37$ weeks by 53.9\%. The average length of patient care was 7 to 8 days with the most hospital room was ICU of $32.9 \%$ and the regular room was 39.5\%. The most common types of heart disorders are peripartum cardiomyopathy and hypertensive heart disease, which is $42.1 \%$. Type of delivery mostly by cesarean section that is equal to $64.5 \%$. The study found that mothers with heart abnormalities were $88.2 \%$ alive and died of $11.8 \%$ after going through labor.

Conclusion: There is a difference between the degree of cardiac abnormalities based on NYHA (New York Heart Association) classification with maternal and infant outcomes in pregnancy with cardiac abnormalities.
\end{abstract}

Key words: Type and Degree of Heart Abnormality, Type of Birth, Outcome of Mother and Infant 


\section{Pendahuluan}

Penyakit jantung pada kehamilan merupakan kehamilan dengan morbiditas dan mortalitas non obstetrik yang penting dan cukup tinggi pada wanita hamil. Angka kejadian kehamilan dengan penyakit jantung dilaporkan terjadi sekitar 0,4 sampai 4\% dari seluruh kehamilan di negara maju. ${ }^{1}$ Di Amerika Serikat angka kejadian kehamilan mencapai 1 sampai $4 \%$ dari kehamilan, dengan mortalitas rata-rata pada wanita hamil dengan New York Heart Association (NYHA) kelas I dan II sebesar $0.4 \%$ hingga $6.8 \%$. Angka ini lebih tinggi lagi pada penderita dengan tingkat keparahan kelas III dan IV. ${ }^{2}$ Hal yang sama juga terjadi di Inggris, angka kematian kehamilan dengan penyakit jantung meningkat dari 1,65 menjadi 2,31 per 100.000 kelahiran pada tahun 1999 ke tahun $2008 .^{3}$

Angka kejadian penyakit jantung dalam kehamilan di Indonesia pada tahun 2005 sampai 2006 adalah sekitar 1,2\% dari jumlah kehamilan, dengan angka mortalitas yang belum diketahui. ${ }^{4}$ Angka kejadian tersebut dapat lebih besar, karena sistem pencatatan atau rekam medis yang belum berjalan dengan baik. Di Rumah Sakit Umum Pusat Dr. Hasan Sadikin Bandung pada tahun 2016 terdapat 42 kasus hamil dengan kelainan jantung yang menjalani persalinan, 65 kasus yang menjalani rawat inap, dan 7 kasus mortalitas. Wanita hamil dengan penyakit jantung berisiko tinggi untuk komplikasi kardiovaskular selama kehamilan dan juga memiliki insidensi komplikasi neonatal yang lebih tinggi. ${ }^{5,6}$ Terdapat berbagai faktor risiko yang meningkatkan terjadinya kehamilan dengan kelainan jantung, diantaranya adalah peningkatan usia pada kehamilan pertama, peningkatan prevalensi faktor risiko kardiovaskular, yaitu diabetes, hipertensi, dan obesitas. ${ }^{5,6,7}$

Oleh karena itu penting dilakukan penelitian sebagai upaya untuk menilai karakteristik dan outcome kehamilan dengan kelainan jantung dan juga menilai perbedaan antara derajat dan jenis kelainan jantung serta jenis persalinan yang digunakan terhadap outcome persalinan baik pada ibu dan bayi di RSUP dr. Hasan Sadikin Bandung.

\section{Metode}

Penelitian ini adalah observasional analitik (cross-sectional). Secara sistematik penelitian dapat digambarkan sebagai berikut. Subjek penelitian adalah semua ibu hamil dengan kelainan jantung yang menjalani persalinan di RSUP dr. Hasan Sadikin Bandung dari tahun 2015 sampai 2017.

Penelitian ini dilaksanakan di Bagian obstetri dan ginekologi, dan Rekam Medis RSUP dr. Hasan Sadikin Bandung. Waktu Penelitian dilaksanakan mulai Desember 2017 sampai Maret 2018.

\section{Hasil}

Pada penelitian ini usia rata-rata ibu yang mengalami kelainan jantung pada kehamilan adalah 30 tahun, paling banyak pada paritas 1 dan 3 yaitu sebesar $31.6 \%$, usia kehamilan saat terjadi persalinan $\geq 37$ minggu sebesar $53.9 \%$. Lama perawatan pasien rata-rata 7 sampai 8 hari dengan ruang rawat yang paling banyak adalah ICU sebesar 32.9\% dan ruang rawat biasa sebesar 39,5\%. Jenis kelainan jantung yang paling sering adalah kardiomiopati peripartum dan hipertensi, yaitu sebesar $42,1 \%$. Jenis persalinan yang banyak dilakukan adalah seksio sesarea yaitu sebesar $64,5 \%$. Penelitian ini memperoleh bahwa ibu dengan kelainan jantung yang hidup sebesar $88.2 \%$ dan meninggal sebesar $11,8 \%$ setelah menjalani persalinan. 


\section{Tabel 1 Gambaran Karakteristik Ibu}

\begin{tabular}{|c|c|}
\hline Variabel & $\mathrm{N}=76$ \\
\hline \multicolumn{2}{|l|}{ Usia Ibu (tahun) } \\
\hline Mean \pm Std & $30.67 \pm 6.672$ \\
\hline Median & 30.00 \\
\hline Range & $16.00-45.00$ \\
\hline \multicolumn{2}{|l|}{ Usia kehamilan } \\
\hline$<28$ minggu & $1(1.3 \%)$ \\
\hline$\geq 28-<37$ minggu & $34(44.7 \%)$ \\
\hline$\geq 37$ minggu & $41(53.9 \%)$ \\
\hline \multicolumn{2}{|l|}{ Lama Perawatan } \\
\hline Mean \pm Std & $7.88 \pm 4.901$ \\
\hline Median & 7.00 \\
\hline Range & $1.00-30.00$ \\
\hline \multicolumn{2}{|l|}{ Left ventricular ejection fraction } \\
\hline \multicolumn{2}{|l|}{$(L V E F)$ sebelum persalinan } \\
\hline Mean \pm Std & $49.68 \pm 9.178$ \\
\hline Median & 50.00 \\
\hline \multicolumn{2}{|l|}{ Range } \\
\hline \multirow{2}{*}{\multicolumn{2}{|c|}{$\begin{array}{l}\text { Left ventricular ejection fraction } \\
(L V E F) \text { setelah persalinan }\end{array}$}} \\
\hline & \\
\hline Mean \pm Std & $53.97 \pm 10.892$ \\
\hline Median & 54.00 \\
\hline Range (min-max) & $34.00-86.00$ \\
\hline \multicolumn{2}{|l|}{ Jenis kelainan Jantung } \\
\hline Kardiomiopati peripartum & $32(42.1 \%)$ \\
\hline Hipertensi & $32(42.1 \%)$ \\
\hline Kelainan jantung bawaan & $6(7.9 \%)$ \\
\hline Rheumatic Heart Disease & $6(7.9 \%)$ \\
\hline \multicolumn{2}{|l|}{ Jenis Persalinan } \\
\hline Seksio sesarea & $49(64.5 \%)$ \\
\hline Partus Buatan Pervaginam & $19(25.0 \%)$ \\
\hline Spontan & $8(10.5 \%)$ \\
\hline \multicolumn{2}{|l|}{ Outcome Ibu } \\
\hline Hidup & $67(88.2 \%)$ \\
\hline Meninggal & $9(11.8 \%)$ \\
\hline \multicolumn{2}{|l|}{ Ruang rawat Ibu } \\
\hline Intensive care unit (ICU) & $25(32.9 \%)$ \\
\hline High care unit $(H C U)$ & $21(27.6 \%)$ \\
\hline Ruang rawat biasa & $30(39.5 \%)$ \\
\hline
\end{tabular}


Tabel 2 Gambaran Karakteristik Bayi

\begin{tabular}{cc}
\hline \multicolumn{1}{c}{ Variabel } & $\mathbf{N}=\mathbf{7 6}$ \\
\hline Skor APGAR 1' bayi & \\
Mean \pm Std & $6.42 \pm 1.878$ \\
Median & 7.00 \\
Range (min-max) & $0.00-9.00$ \\
Skor APGAR 5' bayi & \\
Mean \pm Std & $8.59 \pm 1.790$ \\
Median & 9.00 \\
Range (min-max) & $0.00-10.00$ \\
Asfiksasi Berat & $5(6.6 \%)$ \\
Asfiksasi Sedang & $25(32.9 \%)$ \\
Tidak Asfiksasi & $46(60.5 \%)$ \\
Berat badan bayi & \\
Kecil masa kehamilan & $7(9.2 \%)$ \\
Sesuai masa kehamilan & $68(89.5 \%)$ \\
Besar masa kehamilan & $1(1.3 \%)$ \\
\hline
\end{tabular}

Tabel 3 Perbedaan antara Jenis Kelainan Jantung dengan Outcome Ibu dan Bayi

\begin{tabular}{|c|c|c|c|c|c|}
\hline \multirow[b]{2}{*}{ Variabel } & \multicolumn{5}{|c|}{ Jenis Kelainan Jantung } \\
\hline & $\begin{array}{l}\text { Kardiomiopati } \\
\text { Peripartum } \\
\text { N=32 }\end{array}$ & $\begin{array}{c}\text { Penyakit } \\
\text { jantung } \\
\text { hipertensi } \\
\mathrm{N}=32 \\
\end{array}$ & $\begin{array}{c}\text { Kelainan jantung } \\
\text { bawaan } \\
N=6\end{array}$ & $\begin{array}{c}\text { Penyakit } \\
\text { jantung } \\
\text { rheumatik } \\
\quad \mathrm{N}=6\end{array}$ & Nilai P \\
\hline Ruang Rawat & & & & & 0.250 \\
\hline$I C U$ & $13(40,6 \%)$ & $9(28,1 \%)$ & $3(50,0 \%)$ & $0(0.0 \%)$ & \\
\hline$H C U$ & $10(31,3 \%)$ & $7(21,9 \%)$ & $2(33,3 \%)$ & $2(33.3 \%)$ & \\
\hline Biasa & $9(28.1 \%)$ & $16(50,0 \%)$ & $1(16,7 \%)$ & $4(66.7 \%)$ & \\
\hline Lama Perawatan & & & & & 0,226 \\
\hline Mean \pm Std & $8,96 \pm 4,829$ & $6,71 \pm 3,07$ & $9,50 \pm 11,414$ & $6,66 \pm 2,42$ & \\
\hline Median & 8,00 & 6,00 & 3,50 & 7,00 & \\
\hline $\begin{array}{l}\text { Range } \\
\text { (min-max) }\end{array}$ & $1,00-22,00$ & $2.00-16.00$ & $2.00-30.00$ & $3,00-10,00$ & \\
\hline \multicolumn{5}{|c|}{ Perubahan Left ventricular ejection fraction ( $\triangle L V E F$ ) } & 0,184 \\
\hline Meningkat & $17(53,1 \%)$ & $12(37,5 \%)$ & $1(16,7 \%)$ & $5(83,3 \%)$ & \\
\hline Tetap & $10(31,3 \%)$ & $11(34,4 \%)$ & $2(33,3 \%)$ & $1(16,7 \%)$ & \\
\hline Menurun & $5(15,6 \%)$ & $9(28,1 \%)$ & $3(50,0 \%)$ & $0(0,0 \%)$ & \\
\hline Berat badan bayi & & & & & 0,798 \\
\hline $\begin{array}{l}\text { Kecil masa } \\
\text { kehamilan }\end{array}$ & $4(12,5 \%)$ & $2(6,3 \%)$ & $1(16,7 \%)$ & $0(0,0 \%)$ & \\
\hline $\begin{array}{l}\text { Sesuai masa } \\
\text { kehamilan }\end{array}$ & $28(87,5 \%)$ & $29(90,6 \%)$ & $5(83,3 \%)$ & $6(100,0 \%)$ & \\
\hline $\begin{array}{l}\text { Besar masa } \\
\text { kehamilan }\end{array}$ & $0(0,0 \%)$ & $1(3,1 \%)$ & $0(0,0 \%)$ & $0(0,0 \%)$ & \\
\hline
\end{tabular}


Tabel 4 Perbedaan antara Derajat Kelainan Jantung dengan Outcome Ibu dan Outcome Bayi

\begin{tabular}{|c|c|c|c|c|c|}
\hline \multirow[b]{2}{*}{ Variabel } & \multicolumn{4}{|c|}{ Derajat Kelainan Jantung } & \multirow[b]{2}{*}{ Nilai p } \\
\hline & $\begin{array}{l}\text { FC I } \\
N=2\end{array}$ & $\begin{array}{l}\text { FC II } \\
N=19\end{array}$ & $\begin{array}{c}\text { FC III } \\
\mathbf{N}=\mathbf{2 0}\end{array}$ & $\begin{array}{l}\text { FC IV } \\
N=35\end{array}$ & \\
\hline Outcome Ibu & & & & & 0.042 \\
\hline Hidup & $2(100,0 \%)$ & $18(94,7 \%)$ & $19(95,0 \%)$ & $28(80,0 \%)$ & \\
\hline Meninggal & $0(0,0 \%)$ & $1(5,3 \%)$ & $1(5,0 \%)$ & $7(20,0 \%)$ & \\
\hline Ruang rawat & & & & & 0.041 \\
\hline ICU & $0(0,0 \%)$ & $5(26,3 \%)$ & $5(25,0 \%)$ & $15(42,9 \%)$ & \\
\hline $\mathrm{HCU}$ & $0(0,0 \%)$ & $4(21,1 \%)$ & $9(45,0 \%)$ & $8(22,9 \%)$ & \\
\hline $\begin{array}{l}\text { Ruang rawat } \\
\text { biasa }\end{array}$ & $2(100,0 \%)$ & $10(52,6 \%)$ & $6(30,0 \%)$ & $12(34,3 \%)$ & \\
\hline Lama Perawatan & & & & & 0.038 \\
\hline Mean \pm Std & $3,50 \pm 2,121$ & $7,26 \pm 6,623$ & $8,35 \pm 2,621$ & $9,22 \pm 4,929$ & \\
\hline Median & 3,50 & 7,00 & 8,50 & 7,00 & \\
\hline $\begin{array}{l}\text { Range } \\
\text { (min-max) }\end{array}$ & $2,00-5,00$ & $1,00-30,00$ & $2,00-12,00$ & $2,00-22,00$ & \\
\hline Outcome Bayi & & & & & 0.049 \\
\hline Asfiksasi Berat & $0(0,0 \%)$ & $3(15,8 \%)$ & $0(0,0 \%)$ & $2(5,7 \%)$ & \\
\hline Asfiksasi Sedang & $0(0,0 \%)$ & $6(31,6 \%)$ & $7(35,0 \%)$ & $12(34,3 \%)$ & \\
\hline Tidak Asfiksasi & $2(100,0 \%)$ & $10(52,6 \%)$ & $13(65,0 \%)$ & $21(60,0 \%)$ & \\
\hline
\end{tabular}

Pada tabel 1 paling banyak diperoleh kondisi bayi dengan asfiksia sedang sebesar $32,9 \%$ dan tidak asfiksia sebesar $60,5 \%$ serta pertumbuhan bayi sebagian besar sesuai masa kehamilan yaitu sebesar $89.5 \%$.

Pada Tabel 2 dianalisis perbedaan antara jenis kelainan jantung Kardiomiopati Peripartum, Hipertensi, Penyakit Jantung Bawaan, dan Penyakit jantung rheumatik dengan outcome ibu meliputi: kematian ibu selamadansetelah persalinan, lamaperawatan, jenis ruang perawatan, dan perubahan LVEF. Berdasarkan analisis uji perbedaan antara seluruh variabel jenis kelainan jantung dengan outcome ibu diperoleh $\mathrm{p}>0,05$. Sehingga pada penelitian ini tidak terdapat perbedaan antara setiap variabel jenis kelainan jantung dengan outcome ibu. Perbedaan antara jenis kelainan jantung seperti kardiomiopati peripartum, hipertensi, penyakit jantung bawaan, dan penyakit jantung rheumatik dengan outcome bayi meliputi: kebugaran bayi (asfiksia), pertumbuhan bayi (kurva Lubchenco) berdasarkan hasil analisis statistika uji perbedaan menggunakan uji Chi-Square dengan alternatif uji Kolmogorov Smirnov dan Exact Fisher apabila syarat dari Chi-Square tidak terpenuhi, antara seluruh variabel jenis kelainan jantung dengan outcome bayi diperoleh $p>0,05$. Sehingga pada penelitian ini tidak terdapat hubungan atau korelasi antara setiap variabel jenis kelainan jantung dengan outcome bayi.

Pada tabel 3 dinilai perbedaan antara jenis persalinan seperti seksio sesarea, pervaginam spontan dan buatan dengan outcome ibu meliputi: kematian ibu selama dan setelah persalinan, lama perawatan, jenis ruang perawatan, dan perubahan LVEF. Berdasarkan analisis uji perbedaan antara seluruh variabel jenis kelainan jantung dengan outcome ibu diperoleh $\mathrm{p}>0,05$. Sehingga 
pada penelitian ini tidak terdapat perbedaan antara setiap variabel jenis persalinan dengan outcome ibu.

Perbedaan antara jenis persalinan seperti seksio sesarea, pervaginam spontan dan buatan dengan outcome bayi meliputi: kebugaran bayi (asfiksia), pertumbuhan bayi (kurva Lubchenco) berdasarkan hasil analisis perbedaan antara seluruh variabel jenis persalinan dengan outcome bayi diperoleh $p>0,05$. Sehingga pada penelitian ini tidak terdapat perbedaan antara setiap variabel jenis kelainan jantung dengan outcome bayi.

Tabel 4 pada penelitian ini menilai perbedaan antara derajat kelainan jantung FC I, II, III dan IV dengan outcome ibu dan bayi meliputi: kematian ibu selama dan setelah persalinan, lama perawatan, jenis ruang perawatan, dan derajat asfiksia bayi. Berdasarkan analisis uji perbedaan ChiSquare dengan alternatif uji Exact Fisher antara seluruh variable derajat kelainan jantung dengan outcome ibu diperoleh $p<0,05$. Sehingga pada penelitian ini didapatkan perbedaan antara setiap variabel derajat kelainan jantung dengan outcome ibu dan bayi.

\section{Pembahasan}

Penelitian yang dilakukan oleh Qin tahun 2014 memperoleh hasil yang sama yakni umur pasien hamil dengan kelainan jantung sebanyak $87,1 \%$ berada pada usia 18 sampai 35 tahun, dengan paling banyak pada paritas 1 yaitu sebesar $80 \%$, Usia kehamilan saat terjadi persalinan $\geq 37$ minggu sebesar $75,5 \%$. Jenis kelainan jantung yang paling sering adalah hipertensi dan penyakit jantung bawaan, masing-masing sebesar 37,9\% dan $26,7 \%$. Jenis persalinan yang banyak dilakukan adalah pervaginam yaitu sebesar $55,5 \%$. Penelitian ini memperoleh bahwa ibu dengan kelainan jantung yang hidup sebesar $90 \%$ dan meninggal sebesar $10 \%$ setelah menjalani persalinan. ${ }^{8}$ Penelitian yang dilakukan oleh Samuel tahun 2001 memperoleh hasil yang juga hampir sama yaitu umur pasien hamil dengan kelainan jantung sebanyak $86 \%$ berada pada usia 18 sampai 35 tahun, dengan paling banyak pada paritas 1 yaitu sebesar $58 \%$, usia kehamilan saat terjadi persalinan $\leq 28$ minggu sebesar $69 \%$. Jenis kelainan jantung yang paling sering adalah penyakit jantung bawaan dan hipertensi masing-masing sebesar $74 \%$ dan $22 \%$. Jenis persalinan yang banyak dilakukan adalah pervaginam buatan yaitu sebesar $73 \%{ }^{10,11}$ Penelitian ini memperoleh bahwa ibu dengan kelainan jantung yang hidup sebesar 99\% dan meninggal sebesar 1\% setelah menjalani persalinan.

Pada penelitian ini paling banyak diperoleh kondisi bayi dengan asfiksia sedang sebesar 32,9\% dan tidak asfiksia sebesar $60,5 \%$ serta pertumbuhan bayi sebagian besar sesuai masa kehamilan yaitu sebesar $89,5 \%$.

Penelitian yang dilakukan oleh Qin tahun 2014 juga memperoleh hasil yang hampir sama yaitu kondisi bayi dengan asfiksia sebesar $16 \%$ dan tidak asfiksia sebesar $84 \%$ serta pertumbuhan bayi sebagian besar sesuai masa kehamilan yaitu sebesar $85 \%$. Penelitian yang dilakukan oleh Samuel tahun 2001 juga memperoleh hasil yang hampir sama yaitu kondisi bayi dengan asfiksia sebesar $20 \%$ dan tidak asfiksia sebesar $80 \%$ serta pertumbuhan bayi sebagian besar sesuai masa kehamilan yaitu sebesar $78 \%{ }^{8}$

Penelitian yang dilakukan oleh Fett tahun 2006 yang menilai hubungan antara jenis kelainan jantung seperti kardiomiopati peripartum, hipertensi, penyakit jantung bawaan, dan penyakit jantung rheumatik dengan outcome ibu dan bayi memperoleh hasil yang berbeda yaitu terdapat perbedaan outcome ibu dan bayi pada penyakit jantung kardiomiopati peripartum dengan penyakit Jantung bawaan. kardiomiopati peripartum mempunyai outcome ibu dan bayi yang lebih buruk dibandingkan kelainan jantung yang lain. ${ }^{9}$ 
Penelitian yang dilakukan oleh Avilla tahun 2002 yang menilai hubungan antara jenis kelainan jantung seperti kardiomiopati peripartum, hipertensi, dan penyakit jantung bawaan dengan outcome ibu dan bayi memperoleh hasil yang berbeda yaitu prognosis ibu dan bayi pada kardiomiopati peripartum lebih buruk dibandingkan jenis kelainan jantung lain, penyakit jantung hipertensi maupun penyakit jantung bawaan. ${ }^{10}$

Hal ini juga terjadi pada penelitian ini, kemungkinan disebabkan oleh karena penyakit jantung yang berkaitan dengan hipertensi dapat segera mengalami perbaikan setelah regulasi tekanan darah dan penyakit jantung bawaan yang telah melewati masa krisis persalinan dan proses melahirkan. Pada kardiomiopati peripartum, karena banyak faktor yang mempengaruhi munculnya penyakit, dibutuhkan periode yang cukup lama untuk perbaikan maternal. ${ }^{10,11,12}$

Perlu elaborasi tentang kecenderungan kardiomiopati peripartum di Indonesia apakah berbeda dengan di tempat lain dan apa faktor risiko yang membedakannya.

Penelitian yang dilakukan oleh Magee tahun 2014 juga menilai perbedaan antara jenis persalinan seperti seksio sesarea dan pervaginam dengan outcome ibu dan bayi memperoleh hasil yang sama yaitu tidak terdapat hubungan dan perbedaan outcome ibu dan bayi dengan jenis persalinan baik seksio sesarea maupun pervaginam. ${ }^{14}$

Penelitian yang dilakukan oleh Siu tahun 2001 yang juga menilai perbedaan antara jenis persalinan seperti seksio sesarea, pervaginam spontan dan buatan dengan outcome ibu dan bayi memperoleh hasil yang sama yaitu tidak terdapat hubungan dan perbedaan outcome ibu dan bayi dengan jenis persalinan baik seksio sesarea maupun pervaginam. ${ }^{15}$

Pada penelitian ini didapatkan rata-rata LVEF pasien kardiomiopati peripartum saat didiagnosis 39 dan sebagian besar mengalami kenaikan $L V E F$. Sedangkan prognosis buruk kardiomiopati peripartum terjadi pada $L V E F$ awal $<30 .{ }^{13}$ Sehingga pada penelitian ini jenis kelainan jantung kardiomiopati peripartum mempunyai outcome yang sama dengan kelainan jantung yang lain.

Bagi kebanyakan wanita hamil dengan penyakit jantung, persalinan pervaginam (dengan ekstraksi forsep) sangat dianjurkan. Seksio sesarea elektif dianjurkan pada kasus sindrom Marfan, komplikasi aneurisma aorta, sindrom Eisenmenger dan infark miokard disertai gagal jantung dilanjutkan dengan sterilisasi untuk menghindari kondisi yang memburuk pada saat melahirkan. ${ }^{16}$

Persalinan pervaginam (dengan akselerasi) dan pemberian analgesia regional dapat menurunkan cardiac stress akibat nyeri persalinan, dan tindakan percepatan kala II seperti ekstraksi forsep dapat meminimalkan cardiac stress pada fase persalinan atau kala kedua. Seksio sesarea memiliki manfaat karena dapat mengurangi efek hemodinamik pada persalinan, namun terdapat efek lain akibat anestesia, pergeseran volume darah, bantuan ventilasi yang juga dapat berdampak pada hemodinamik, sehingga tidak ada perbedaan tindakan pervaginam maupun seksio sesarea. Seksio sesarea dilakukan hanya bila ada indikasi obstetri. Hal utama yang perlu diperhatikan adalah tindakan persalinan membutuhkan monitoring ketat hemodinamik oleh tim spesialistik multidisiplin. ${ }^{17,18,19,20}$

Perbedaan antara derajat kelainan jantung FC I, II, III dan IV dengan outcome bayi meliputi: kebugaran bayi (asfiksia), pertumbuhan bayi (kurva Lubchenco) berdasarkan hasil analisis statistika uji perbedaan antara seluruh variabel derajat kelainan jantung dengan outcome bayi diperoleh $\mathrm{p}<0,05$. Sehingga pada penelitian ini terdapat perbedaan antara setiap variabel derajat kelainan jantungdengan outcome bayi. Penelitian yang dilakukan oleh Magee tahun 2014 yang menilai perbedaan antara derajat kelainan jantung dengan outcome ibu dan bayi. Penelitian tersebut memperoleh 
hasil bahwa FC yang paling banyak ditemukan adalah I dan II, yaitu sebesar 91\% dan disimpulkan bahwa terdapat hubungan positif antara derajat kelainan jantung dengan outcome ibu dan bayi, sehingga semakin berat derajat kelainan jantung maka semakin buruk outcome ibu dan bayi. ${ }^{14}$

Penelitian yang dilakukan oleh Siu tahun 2001 yang menilai perbedaan antara derajat kelainan jantung dengan outcome ibu dan bayi. Penelitian tersebut juga memperoleh hasil yang sama bahwa terdapat hubungan positif antara derajat kelainan jantung dengan outcome ibu dan bayi, sehingga semakin berat derajat kelainan jantung maka semakin buruk outcome ibu dan bayinya. ${ }^{15}$

Pada kelainan jantung dengan NYHA lebih dari FC II, tubuh tidak dapat menoleransi beban hemodinamik pada kehamilan akibatnya tidak terbentuk sistem sirkulasi kardiovaskular yang menunjang kondisi hamil. Hal ini mengakibatkan tubuh mengalami hipoksia secara menyeluruh apabila hal tersebut berlanjut dalam jangka waktu yang relatif lama akan menimbulkan outcome yang buruk baik pada ibu maupun bayi. ${ }^{15}$ Simpulan dengan penatalaksanaan yang selama ini dijalankan, dari penelitian ini didapatkan tidak terdapat perbedaan antara jenis kelainan jantung dengan outcome ibu dan bayi pada kehamilan dengan kelainan jantung. Tidak terdapat perbedaan antara jenis persalinan dengan outcome ibu dan bayi pada kehamilan dengan kelainan jantung. Dan didapatkan perbedaan antara derajat kelainan jantung dengan outcome ibu dan bayi pada kehamilan dengan kelainan jantung. Hal ini dapat terjadi karena pasien datang sudah dalam kondisi yang cukup parah sehingga meskipun dengan fasilitas yang tersedia kondisinya tidak membaik.

Sebaiknya pasien yang memiliki potensi untuk mengalami komplikasi pada kehamilannya terutama karena kelainan jantung dapat ditangani lebih dini pada fasilitas-fasilitas kesehatan primer, termasuk pada skrining, konseling, maupun penyuluhan alat kontrasepsi pada kelompok berisiko.

\section{Daftar Pustaka}

1. Simpson LL. Maternal cardiac disease: update for the clinician. Obstet Gynecol. 2012;119(2):345-59.

2. Lewis G. The Confidential Enquiry into Maternal and Child Health (CEMACH). Saving Mothers' Lives: reviewing maternal deaths to make motherhood safer 2003-2005. The Seventh Report of the Confidential Enquiries into Maternal Deaths in the UK. CEMACH. 2007;1(1):54.

3. Wilkinson $\mathrm{H}$, Trustees, Advisers $\mathrm{M}$. Saving mothers' lives. Reviewing maternal deaths to make motherhood safer: 2006-2008. The Eighth Report on Confidential Enquiries Into Maternal Death in United Kingdom. BJOG. 2011;118(11):1402-3.

4. Sarvasti D, Boestan I. Kehamilan dan Penyakit Jantung. In: Boestan I, editor. Penyakit Jantung \& Kehamilan. Surabaya: Airlangga University Press; 2007. p. 30.

5. Elkayam U, Goland S, Pieper PG, Silversides CK. High-risk cardiac disease in pregnancy: Part II. J Am Coll Cardiol. 2016;68(5):502-16.

6. Thompson JL, Kuklina EV, Bateman BT, Callaghan WM, James AH, Grotegut CA. Medical and obstetric Outcomes among pregnant women with congenital heart disease. Obstet Gynecol. 2015;126(2):346.

7. Fretts RC, Schmittdiel J, McLean FH, Usher RH, Goldman MB. Increased maternal age and the risk of fetal death. $\mathrm{N}$ Engl J Med. 2005;333(15):953-7.

8. Cunningham FG, Leveno KJ. Childbearing among older women the message is cautiously optimistic. N Engl J Med. 2005;333:1002. 
9. Fett JD, Ansari AA, Sundstrom JB, Combs GF. Peripartum cardiomyopathy: a selenium disconnection and an autoimmune connection. Int $\mathrm{J}$ Cardiol. 2010;86(2):311-610. Siu SC, Colman JM, Sorensen S, Smallhorn JF, Farine D, Amankwah KS, et al. Adverse neonatal and cardiac Outcomes are more common in pregnant women with cardiac disease. Circulation. 2010;105(18):217984.

10. Pearson GD, Veille J-C, Rahimtoola S, Hsia J, Oakley CM, Hosenpud JD, et al. Peripartum cardiomyopathy: national heart, lung, and blood institute and office of rare diseases (national institutes of health) workshop recommendations and review. JAMA. 2010;283(9):1183-8. Elkayam U, Bitar F. Valvular heart disease and pregnancy: part II: prosthetic valves. J Am Coll Cardiol. 2005;46(3):403-10.

11. Yancy CW, Jessup M, Bozkurt B, Butler J, Casey DE, Drazner $\mathrm{MH}$, et al. $2013 \mathrm{ACCF} / \mathrm{AHA}$ guideline for the management of heart failure: executive summary: a report of the American College of Cardiology Foundation/ American Heart Association Task Force on practice guidelines. Circulation. 2013;128(16):1810-52.

12. European Society of Gynecology (ESG), Association for European Paediatric Cardiology (AEPC), German Society for Gender Medicine (DGesGM), RegitzZagrosek V, Blomstrom Lundqvist C, Borghi $\mathrm{C}$, et al. ESC Guidelines on the management of cardiovascular diseases during pregnancy: the Task Force on the Management of Cardiovascular Diseases during Pregnancy of the European Society of Cardiology (ESC). Eur Heart J. 2011;32(24):3147-97.

13. Sliwa K, Hilfiker-Kleiner D, Petrie MC, Mebazaa A, Pieske B, Buchmann $\mathrm{E}$, et al. Current state of knowledge on aetiology, diagnosis, management, and therapy of peripartum cardiomyopathy: a position statement from the Heart Failure Association of the European Society of Cardiology Working Group on peripartum cardiomyopathy. Eur J Heart Fail. 2010;12(8):767-78.

14. Magee LA, Pels A, Helewa M, Rey E, von Dadelszen P, Audibert F, et al. Diagnosis, evaluation, and management of the hypertensive disorders of pregnancy: executive summary. J Obstet Gynaecol Can. 2014;36(5):416-38.

15. Siu SC, Sermer M, Colman JM, Alvarez $\mathrm{AN}$, Mercier L-A, Morton BC, et al. Prospective multicenter study of pregnancy Outcomes in women with heart disease. Circulation. 2011;104(5):51521.

16. Thorne S. Pregnancy in heart disease. Heart. 2014;90(4):450-6.

17. Robson S, Dunlop W, Moore M, Hunter S. Haemodynamic changes during the puerperium: a Doppler and M-mode echocardiographic study. $\mathrm{Br} \mathrm{J}$ Obstet Gynaecol. 2007;94(11):1028-39.

18. Metcalfe J, Ueland K. Maternal cardiovascular adjustments to pregnancy. Prog Cardiovasc. 2007;16(4):363-74.

19. Elkayam U, Gleicher N. Hemodynamics and cardiac function during normal pregnancy and the puerperium. In: Elkayam U, Gleicher N, editors. Cardiac Problems in Pregnancy. 2nd ed. New York: Liss; 2000. p. 5-24.

20. Bonow RO, Carabello BA, Chatterjee K, de Leon AC, Faxon DP, Freed MD, et al. ACC/AHA 2006 practice guidelines for the management of patients with valvular heart disease: executive summary: a report of the American College of Cardiology/ American Heart Association Task Force on Practice Guidelines (writing committee to revise the 1998 guidelines for the management of patients with valvular heart disease) developed in collaboration with the Society of Cardiovascular 
Anesthesiologists endorsed by the Society for Cardiovascular Angiography and Interventions and the Society of Thoracic Surgeons. J Am Coll Cardiol. 2010;48(3):598-675. 